\title{
Wieder da! Der „Lebkuchenkongress“ startet 2017 in seiner neuen Heimat
}

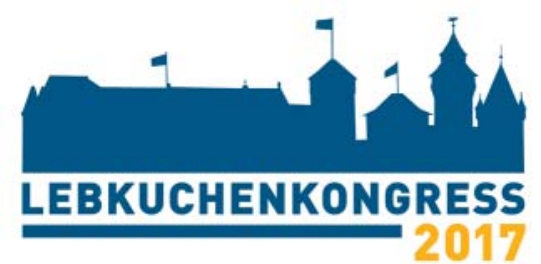

Fortbildungskongress für Assistenzpersonal in der Radiologie, Nuklearmedizin und Strahlentherapie

Die beliebte hochkarätige Fortbildungsveranstaltung, kurz "Lebkuchenkongress" genannt, hat nach einjähriger Pause mit der

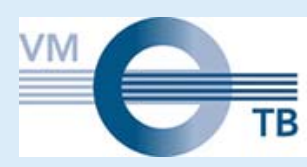

VEREINIGUNG MEDIZINISCH-TECHNISCHER BERUFE

in der Deutschen Röntgengesellschaft e.V.

Meistersingerhalle im Herzen von Nürnberg eine neue Heimat für die nächsten Jahre gefunden.

In diesem Jahr findet der Kongress ausnahmsweise am dritten Adventswochenende statt - 15./16. Dezember 2017. In den Folgejahren wird der Kongress wieder an seinem angestammten Platz, dem zweiten Advent, stattfinden.
NEU ab 2017: Ab sofort hat der Lebkuchenkongress eine eigene Homepage. Auf www.lebkuchenkongress.de finden Sie immer das komplette, tagesaktuelle Programm, die Möglichkeit zur Online-Anmeldung sowie viele weitere Informationen rund um den größten MTRA-Kongress in Deutschland. 